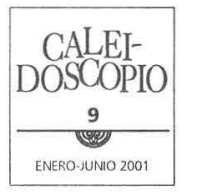

\title{
Revolución, prensa y legitimidad politica. El caso de la Convención de Aguascalientes
}

LUCIANO RAMIREZ HURTADO

Departamento de Historia/UAA

LA REvoluCión Y LA PRENSA ILUSTRADA

\begin{abstract}
Aurelio de los Reyes asienta que desde comienzos del presente siglo, las imágenes fotográficas ocuparon un lugar cada vez más importante en publicaciones periódicas tales como magazines, revistas y libros ilustrados. ${ }^{1}$ Durante el período de la lucha armada este proceso continuó. A la par que se tomaba conciencia de la importancia de la presencia gráfica en las distintas ediciones, se desarrollaba la profesión del reportero gráfico.

Desde el comienzo de la lucha contra el régimen del general Huerta, Venustiano Carranza se preocupó por atraer a los intelectuales al movimiento constitucionalista. ${ }^{2}$ Intelectuales de distintos signos políticos que sirvieron a las diferentes autoridades constitucionalistas, pronto se percataron de que la prensa podría convertirse en un muy importante medio de propaganda política del movimiento.
\end{abstract}

1 Citado en Rebeca Monroy Nasr, «Enrique Díaz y fotografías de actualidad. (De la nota gráfica al fotoensayo)», en Historia Mexicana, 1998, XLVIII:2 (190) (oct.-dic.), pp. 379-380.

2 Hans Werner Tobler, La Revolución mexicana. Transformación social y cambio político, 1876-1940, Alianza Editorial, México, 1994, p.74. 
Una vez que las tropas constitucionalistas hubieron ocupado la ciudad de México, el Primer jefe se dio a la tarea de poner bajo control a la prensa capitalina de reciente creación. El subsecretario del despacho de Gobernación, quizás a instancias de Carranza, nombró a Alfredo Breceda (secretario particular del Varón de Cuatro Ciénegas) director general de la prensa constitucionalista. El criterio que normó dicha función fue:

... unificar la orientación política de la prensa revolucionaria dentro de los ideales sustentados por el constitucionalismo, ya que éste, por necesidades del momento y por circunstancias especiales de la situación, tiene que controlar y de hecho controla a los diarios de información recientemente fundados en esta Capital. ${ }^{3}$

Los diarios a los que alude Breceda son El Liberal y El Pueblo. El primer número de El Liberal, órgano del constitucionalismo, apareció el 18 de agosto de 1914; fue dirigido sucesivamente por Jesús Urueta, Gerzayn Ugarte, Ciro B. Ceballos y Anastasio Rojas. Tuvo como colaboradores a Luis Cabrera, Armando Morales Puente, José Ugarte, Juan Neftalí Amador, Heriberto Barrón, Jorge Useta, Luis Manuel Rojas, José Natividad Macías y algunos otros que escribieron bajo seudónimo. ${ }^{4}$ Inició como Director del diario el Lic. Jesús Urueta, fungiendo como Jefe de Redacción el periodista Gerzayn Ugarte. Luego, éste asumió provisionalmente la dirección, debido a que Urueta fue nombrado «representante intelectual, político y diplomático» de México en los países de

3 El Liberal, México, D.F., 6 de octubre de 1914. [En adelante, dado que todos los diarios y revistas consultados fueron editados en la ciudad de México, se prescindirá de este dato, anotando enseguida del título de la publicación la fecha respectiva.]

4 Diccionario Histórico y Biográfico de la Revolución Mexicana, México, Instituto Nacional de Estudios Históricos de la Revolución Mexicana, 1991, Tomo II, [Distrito Federal], p. 742; El Liberal, 18 de agosto de1914, 27 de septiembre de 1914; 10, 11, 17, 19, 21, 22, 24, 26, 27, 28 de octubre de 1914, 2 y 3 de noviembre de1914. 
América del Sur, ${ }^{5}$ hasta que fue sustituido por el escritor Ciro B. Ceballos, el 6 de octubre de 1914. ${ }^{6}$

El periódico El Pueblo, diario independiente de la mañana, vio la luz pública el lo. de octubre de 1914 apuntándose en la nota editorial, en coincidencia con Breceda, las tendencias del mismo:

... nos proponemos, hasta donde nuestras fuerzas nos lo permitan, laborar para que los generosos propósitos que dieran victorioso empuje a la revolución, queden definitivamente concretados en realidades políticas, y más que políticas, sociales. ${ }^{7}$

El primer director de este otro órgano del gobierno carrancista fue el señor Antonio Revilla, siendo sustituido tres semanas después por José M. Coéllar, ${ }^{8}$ quien también se había desempeñado como director literario de la revista La Ilustración Semanal. ${ }^{9}$ Colaboraron en su página editorial el Lic. Aquiles Elorduy, el periodista hondureño Matías Oviedo, alguien que escribió bajo el seudónimo «X.X.X.», aunque la mayoría de las editoriales de El Pueblo no fueron signadas. ${ }^{10}$

A juzgar por la trayectoria de ambos diarios, todo parece indicar que en un principio a El Liberal le dieron las autoridades carrancistas mayor realce e importancia. Contaba con mayor cobertura de noticias tanto nacionales como mundiales, constaba de más páginas con variadas secciones, escribían afamados periodistas y jurisconsultos, y se le daba más espacio en sus planas a la presencia gráfica. Sin embargo su existencia fue efímera, pues fue sacrificado por el carrancismo cuando su marcha a

5 El Liberal, 2- de septiembre de 914.

$6 \quad$ El Liberal, 6 de octubre de 1914.

7 El Pueblo, 1 de octubre de 1914, p. 3. (sección Editorial),

8 El Pueblo, 1 y 19 de octubre de 1914.

$9 \quad$ La llustración Semanal, México, D.F., [I], (39), 29 de junio de 1914.

10 El Pueblo, 8, 10, 16, 18, 19, 20-24, 26-31 de octubre de 1914. 
Veracruz. Entonces se decidió proporcionar todo el apoyo a $E l$ Pueblo, escribiendo en sus páginas intelectuales de la talla de Félix F. Palavicini, José Ugarte, Antonio Manero, Diego Arenas Guzmán, Heriberto Barrón, Laura Méndez de Cuenca, Gonzalo de la Parra, Agustín Haro, entre otros. ${ }^{11}$

FotorREPORTEROS Y ENVIADOS ESPECIALES DE LA PRENSA CAPITALINA

El compromiso contraído por la Comisión Permanente de Pacificación con la División del Norte, consistente en realizar la Convención en una ciudad neutral, finalmente se vio coronado por el éxito.

Aguascalientes fue escogida en octubre de 1914 como sede para la realización de la Convención Revolucionaria, con el claro propósito de tratar de evitar la escisión entre las facciones, decidir quién gobernaría el país y en qué forma, así como acordar la elaboración de un programa de gobierno.

Repentinamente Aguascalientes se convirtió en el foco de atención de todo el país y acaparó la atención pública. Los revolucionarios de las distintas facciones, la prensa y la opinión pública volvieron su mirada expectante hacia la capital hidrocálida.

De inmediato los principales diarios de la prensa capitalina mandaron sus enviados especiales. Fotógrafos y periodistas hicieron maletas y se prepararon con todo el equipo necesario para trasladarse a la ciudad de Aguascalientes, estar presente en el lugar de los hechos y cubrir la nota. El seis de octubre partieron hacia Aguascalientes en tren especial, junto con otros delegados, representantes de los periódicos El Liberal (Carlos Quirós y Carlos Muñana, reportero y fotógrafo respectivamente), El Pueblo (Arturo Cisneros, enviado especial), El Radical (Gilberto Torres,

1 Diccionario Histórico y Biográfico de la Revolución Mexicana, México, INEHRM, 1991, Tomo II [Distrito Federal],. p. 790. 
corresponsal) y Nueva Patria (Rafael Machorro). ${ }^{12}$ Unos días más tarde llegaron a esa ciudad los fotógrafos Abraham Lupercio, Agustín Víctor Casasola y H. J. Gutiérrez. Se ignora si fueron por su cuenta o enviados contratados por alguna empresa, lo cierto es que algunas fotografías firmadas por esos fotógrafos se publicaron en La Ilustración Semanal. ${ }^{13}$ Esta revista es de las pocas que reconocieron la autoría de las imágenes allí publicadas, a diferencia de los reporteros gráficos que laboraban para la prensa diaria (periódicos), quienes además de sufrir precarias condiciones de trabajo al gozar de bajos salarios, carecer de garantías laborales y tener escaso reconocimiento a su labor, nunca se les acreditó la autoría de la imágenes impresas. ${ }^{14}$

Por ese entonces Agustín Víctor Casasola había instalado, junto con su amigo Gonzalo Herrerías, una Agencia de Información Fotográfica. Casasola había sido reportero, dejó la redacción para dedicarse a la fotografía de prensa, oficio que cultivó a partir de 1900; a lo largo de su vida se afilió a distintas agrupaciones tales como la Asociación Mexicana de Periodistas (hacia 1903) y la Sociedad de Fotógrafos de Prensa (1912), desaparecida esta última a mediados de 1914, tras el triunfo del constitucionalismo. La experiencia adquirida, las relaciones que cultivó, la prudente distancia que guardó respecto de las distintas posiciones políticas y la colección de fotegrafías que había reunido con obra propia y de otros reporteros, fue lo que le permitió abrir su propia Agencia de Información Fotográfica. ${ }^{15}$ Es posible que muchas de

12 El Liberal, 7 de octubre de 1914; La Ilustración Semanal, [II] (57), 2 de noviembre de 1914.

13 La Ilustración Semanal, [II] (55), 19 de octubre de 1914; [II] (57), 2 de noviembre de 1914; [II] (59), 16 de noviembre de 1914.

14 Rebeca Monroy Nasr, Op. cil., pp. 376-377.

15 Flora Lara Klahr, "México a través de las fotos, Agustin Víctor Casaola \& Cia”, en Siempre! Presencia de México, México, D.F., Número 1639, 1984, pp. 39-41. 
las fotografías publicadas en las distintas revistas ilustradas y en los diversos diarios capitalinos hayan tenido que ver con la agencia de Casasola. Flora Lara afirma que la Agencia de Información Fotográfica montada por Casasola y Cía., en calidad de fotógrafo independiente, fue la primera de esta naturaleza que se instaló en México, «suministrando imágenes a periódicos nacionales y extranjeros de distintas tendencias». ${ }^{16}$ Ello explicaría, quizá, el hecho de que son básicamente las mismas fotos las que circularon y se publicaron de manera simultánea -o casi-, por ejemplo, en la prensa ilustrada como La Semana Ilustrada, La Ilustración Semanal, El Liberal y El Pueblo. El Primer Jefe no quiso asistir a Aguascalientes ni enviar a su representante. Sin embargo, el todavía encargado del Poder Ejecutivo, tuvo el cuidado de mandar a través de sus incondicionales a enviados especiales que estarían informando con prodigalidad a la subsidiada prensa capitalina, prensa controlada por sus amigos los intelectuales.

Es de suponer que el derecho autoral, en materia de producción fotográfica, no estaba totalmente desarrollado en cuanto a legislación se refiere, ${ }^{17}$ aún cuando algunos fotógrafos como $\mathrm{H}$. J. Gutiérrez si tuvieron el cuidado de registrar como de su propiedad las fotografías de su autoría publicadas con la leyenda "Prop. Reg.- Prohibida la reproducción". ${ }^{18}$

Sea como fuere, los reporteros y fotógrafos enviados por la prensa capitalina, tenían el cometido de cubrir en provincia, en este caso Aguascalientes, el evento político más importante de los últimos meses: la Convención Revolucionaria. La función de los enviados especiales consistió en mandar telegramas a la ciu-

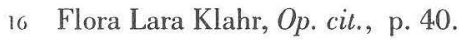

17 Aurelio de los Reyes, Cine y sociedad en México, 1896-1930, Vivir de sueños (1896-1920), Vol. 1, México, Instituto de Investigaciones EstéticasUniversidad Nacional Autónoma de México, 1983, p. 137.

18 La Ilusiración Semanal, [II] (55), 19 de octubre de 1914; [II] (57), 2 de Noviembre de 1914.

136. C A A L 
dad de México, para que la gente de redacción del periódico elaborase la crónica de los debates. Otro tanto debió ocurrir con la prensa de otras ciudades importantes de la República, así como con la prensa extranjera.

\section{Aguascalientes, la Sobresaltada SEDE dE la Convención}

De manera inesperada Aguascalientes pasó a ser «la capital de los ciudadanos armados de México» y se transformó en el «reino de la revolución». ${ }^{19}$ Historiadores, literatos, filósofos y reporteros plasmaron por escrito sus impresiones de ese momento histórico. ${ }^{20}$ Lo deplorable del viaje, las impresiones de la ciudad, el carácter de sus moradores, en fin, la atmósfera que flotaba en el ambiente en los días en que Aguascalientes, ciudad famosa por su actividad febril tanto por los talleres del ferrocarril ahí instalados como por la existencia de la Gran Fundición Central, fue la sede de la denominada por Martín Luis Guzmám "azorada" Convención.

La prensa capitalina publicó, a manera de postales, una serie de fotografías que mostraban los lugares más representativos y atractivos de la ciudad de Aguascalientes. El famoso fotógrafo Carlos Muñana, enviado especial de El Liberal y colaborador de La Ilustración Semanal, selecciónó para los lectores de la ciudad de México el Teatro Morelos, la Fundición Central, los Baños de los Arquitos y el Templo de San Antonio, además de una vista

19 José C. Valadés, Historia general de la Revolución Mexicana, México, SEPEdiciones Cernika, [edición conmemorativa del 75 aniversario de la Revolución mexicana], 1985, T’omo II, pp. 394, 396.

20 José C. Valadés, Op. cil., Tomo III, pp. 394-399; José Vasconcelos, La Tormenla [segunda parte de Ulises Criollo], México, Ediciones Botas, 1948, pp. 168-192; El Liberal, 14 de octubre de 1914; Francisco Ramírez Plancarte, La ciudad de México durante la revolución constitucionalista, México, Impresores Unidos, 1941, pp. 75-78, 104. 
panorámica de la ciudad. ${ }^{21}$ Otro tanto hizo el fotógrafo del diario El Pueblo, que publicó las fotografías donde aparece la Catedral, el Palacio de Gobierno, el Jardín de San Marcos, y seguramente sacadas dé algún archivo una toma aérea de la ciudad y un detalle de la Plaza principal. ${ }^{22}$

Podemos imaginar el ambiente tenso a la vez que excitante que vivió Aguascalientes en esos días. Los habitantes de esa antaño apacible y tranquila ciudad todavía no se recuperaban del susto cuando la ocupación sin resistencỉ de la plaza por parte de las fuerzas constitucionalistas -las autoridades y tropas huertistas habían abandonado con suficiente tiempo la entidad-, pero no por ello carente de incidentes, tan sólo dos meses y medio antes, y que al ocurrir cambios de autoridad, desórdenes e inseguridad pública hubo zozobra entre sus habitantes. Ahora, en octubre de ese mismo año la expectación, efervescencia y excitación llegaron a su punto más alto. Los moradores de Aguascalientes, que tenían fama de pacíficos, industriosos y de ser fervientes católicos, no pudieron menos que ver con asombro el arribo de innumerables forasteros, gente de todas cataduras, muchos de ellos armados. La nueva presencia acrecentada de militares, pertenecientes a distintos grupos revolucionarios, tenía anonadados a los lugareños quienes contemplaron con «ojos muy abiertos... a muchos de estos guerreros, de quienes oyeron relatar prodigiosas aventuras». ${ }^{23}$

La ciudad, de poco más de veinte mil habitantes, experimentó un cambio brusco en su paisaje urbano. Llegaron a Aguascalientes varios millares de forasteros, de modo que los hoteles, mesones y casas de huéspedes, así como la comida, fueron insuficientes para dar albergue y alimento a tanta gente. Fue tal la avalancha de

21 El Liberal, 10 y 11 de octubre de 1914.

22 El Pueblo, 5, 12 y 13 de octubre de 1914.

23 El Liberal, 14 de octubre de 1914; José C. Valadés, Op. cil., 1985, Tomo IV, pp. 38-40. 
concurrentes a la Convención, que los cobertizos y salas de espera de la estación del ferrocarril, así como muchos vagones estacionados en sus patios, fueron habilitados como dormitorios, ${ }^{24} \mathrm{e}$ inclusive los cafés, billares y cantinas, que aunque en condiciones antihigiénicas y de incomodidad, fueron lugares concurridos para pernoctar. ${ }^{25}$ Inclusive algunas residencias particulares, gracias a la intervención del gobernador Alberto Fuentes Dávila o por propia iniciativa de sus acaudalados y oportunistas dueños que buscaban quedar bien con quienes posiblemente formarían la «nueva pléyade mexicana», ${ }^{26}$ dieron aposento a algunos delegados a la Convención. ${ }^{27}$

Desde los días seis y siete de octubre fueron llegando en trenes especiales, procedentes de Torreón y ciudad de México, delegados que iban a la Convención. En la estación los recibió «entusiastamente» una curiosa muchedumbre, «una masa humana que pugnaba por ser la primera en ver el descenso de los viajeros al andén" ferrocarrilero. Asimismo el oportunismo político de algunos prominentes aguascalentenses no se hizo esperar, ya que

Con todo género de consideraciones fueron recibidos los delegados, quienes ocupando varios carruajes particulares, se dirigieron al Hotel Washington, considerado como el más importante de la población; allí concurrieron a saludar a los viajeros las personas de mayor prestigio político y social de Aguascalientes. ${ }^{28}$

24 Francisco Ramírez Plancarte, Op. cil.,, pp. 75-78; José C. Valadés, $O p$. cil., Tomo IV, pp. 38-40; Martin Luis Guzmán, El águila y la serpiente, México, Porrúa, 1987, [Colección de Escritores Mexicanos], p. 319.

2.5 Francisco Ramírez Plancarte, Op. cil., pp. 75-78.

26 José C. Valadés, Op. cil., Tomo IV, pp. 38-40.

27 Vito Alessio Robles, La Convención Revolucionaria de Aguascalientes, México, INEHRM, 1989, pp. 119-120; Martin Luis Guzmán, Op. cil., pp. 319-321.

28 El Pueblo, 8-de octubre de 1914. 
El Hotel Washington fue el principal punto de reunión. Allí estaban hospedados un buen número de delegados, tanto villistas como carrancistas. Se les ofreció un «lunch» a media tarde del día siete de octubre; un suculento banquete y brindis con champagne, por la noche del día siguiente en el salón del comedor del hotel donde «las mesas bien distribuidas y engalanadas, presentan un aspecto sencillo, y en los platos de cada comensal se ven tarjetas con los nombres de los invitados». ${ }^{29}$ Proliferaron los discursos entusiastas cargados de buenos deseos, tomaron la palabra Eduardo Hay, Álvaro Obregón, Eugenio Aguirre Benavides, Orestes Pereyra y otros. Los delegados intercambiaron expresiones y para ese momento se respiraba -afirmó el reportero de El Pueblo- «un ambiente de marcado optimismo» y camaradería, donde al calor de las burbujas del champagne «reinó el buen humor». Los cuantiosos gastos de ése y los días subsiguientes en cuanto a banquetes, bedidas, puros y sirvientes corrieron a cargo del gobierno del estado, que se vió apurado en su presupuesto. ${ }^{30}$

Súbitamente el ambiente se tornó lúdico, casi carnavalesco. Forasteros y lugareños se volcaron a las calles, plazas y jardines públicos. «Las calles se ven henchidas de personas de todas las clases sociales, y los comentarios se suceden con mucha rapidez. Los balcones están ocupados por las familias más connotadas de Aguascalientes.» ${ }^{31}$

Hacía falta solucionar detalles de logística, pues para el ocho de octubre no se sabía con precisión en que recinto de la ciudad se realizaría la Convención. Arturo Cisneros, corresponsal de $E l$ Pueblo anotó:

29. El Pueblo, 8 de octubre de 1914.

30 Enrique Rodríguez Varela, "La Revolución", en Jesús Cómez Serrano, Aguascalientes en la historia, Tomo I, 1988, pp. 542-543.

31 El Pueblo, 8 de octubre de 1914. 
Se señala como punto propicio para la reunión, el salón de la Cámara de Diputados, en el palacio de gobierno, aunque también se habla del salón de sesiones del Ayuntamiento, pero repito, no se tiene firmeza en el punto en el que los delegados vayan a llevar al terreno de la discusión la forma más adecuada para evitar una sensible ruptura de relaciones entre el señor Carranza y el general Francisco Villa. ${ }^{32}$

A marchas forzadas fue habilitado el Teatro Morelos, ya que fue necesario adquirir sillas para los asistentes, estando listo para iniciar actividades el día diez. Mientras tanto, la ciudad se vestía de fiesta. Las bandas de música interpretaban por doquier las piezas más gustadas y los corridos populares que con «destempladas notas de una charanga», 33 eran cantados por improvisados trovadores en algunos barrios típicos; todo esto proporcionaba a la población diversiones extraordinarias. A las audiciones musicales habría que agregar la algarabía que armaban los niños cuando un tranvía adornado con papel multicolor anunció que habría una corrida en la plaza de toros San Marcos, ${ }^{34}$ o bien, el "desbordamiento de entusiasmo" 35 de la muchedumbre que irrumpía en el Teatro Morelos cada vez que se abrían sus puertas, buscando los inquietos y curiosos lugareños presenciar las sesiones de la Convención. ${ }^{36}$ Uno de esos curiosos que anhelaban ser testigos de un momento histórico tan importante, lo sabemos, fue el profesor José T. Vela Salas.

En cuanto al repertorio de fotografías aparecen con cierta frecuencia varios personajes que acaparan la atención del momen-

32 El Pueblo, 8 de octubre de 1914.

33 El Liberal, 14 de octubre de 1914; Enrique Rodríguez Varela, "La azorada cuna de la Convención", en La Soberana Convención Revolucionaria en Aguascalientes, Aguascalientes, Cobierno del Estado de Aguascalientes, 1990, pp. 112-114.

31 El Liberal, 14 de octubre de 1914.

35 Francisco Ramírez Plancarte, Op. cit., pp. 75-78.

36 Vito Alessio Robles, Op. cil., pp. 133, 143, 145-146; Luis Fernando Amaya, La Soberana Convención Revolucionaria 1914-1916, México, Trillas, 1975, pp. 105-106, 139. 
to, y por consiguiente los fotógrafos siguen con atención sus movimientos y participaciones.

Las sesiones tuvieron lugar en el Teatro Morelos. Aparecen con mucha frecuencia, por supuesto, los integrantes de la mesa directiva de la Convención, instalada en el proscenio del teatro. Destaca la figura del general Antonio I. Villarreal (Presidente), siempre en el centro de la mesa, «gesticulando y atusándose continuamente sus largos mostachos ...». El fondo es siempre la escenografía del teatro Morelos. Otros personajes que acaparan cámara son Alvaro Obregón, dentro y fuera del teatro; «con su elegante uniforme», haciendo guardia a la bandera o firmándola y siempre expectante; Eulalio Gutiérrez, que en breve sería designado presidente provisional de la República, invariablemente vestido de traje y corbata, «...a un observador le hizo pensar en uno de esos vendedores de puerta en puerta que van ofreciendo colchas y ropas de cama pagaderas a plazos. Llevaba un sombrero panamá y un poblado bigote 'como de turco». Roque González Garza, unas ocasiones de civil y otras de militar, con una barba crecida como de «Cristo de pueblo» es descrito por Ramírez Plancarte, escritor anti-convencionista, como de «sonrisa aviesa, [y] barbas de divino rostro de carbonería»; ;7 el general Eduardo Hay, de lentes oscuros y que mostraba a la cámara el lado contrario a su ojo tuerto, al decir de sus contrincantes tenía un «triste aspecto de pastor metodista»; y cuando se acercó por la Convención de Aguascalientes, Francisco Villa.

Dada la situación especial de la ciudad, se consideró conveniente integrar una junta neutral de gobierno, conformada por tres integrantes que representara a distintas facciones revolucionarias. Constituida desde el día siete de octubre por el gobernador del estado, coronel Alberto Fuentes Dávila, y por dos personas más, el general carrancista Guillermo García Aragón y el general villista Fidel Ávila, la función de la junta consistía en lle-

37 Francisco Ramírez Plancarte, Op. cit., pp. 285-286 
var a la práctica la conservación del orden en todo el territorio de Aguascalientes y otorgar garantías tanto a los delegados que asistirían a la Convención como a los pobladores de la entidad.

Desde luego, la Convención que se realizó en Aguascalientes fue cuantitativa y cualitativamente distinta, si la comparamos con la junta a la que convocó Carranza en la ciudad de México. La Convención Revolucionaria de Aguascalientes fue un organismo más representativo que la junta de la ciudad de México, pues acudieron carrancistas, villistas y en breve llegarían también los zapatistas. Esto ocurrió el 27 de octubre. Los delegados zapatistas también fueron acosados por los fotógrafos, y por supuesto, también fueron objeto de acres críticas por parte de los periodistas. $\mathrm{Al}$ general Juan M. Banderas, por ejemplo, le vieron «aspecto de tabernero». A los zapatistas se les ve sentados a la hora de los debates, platicando, con miradas hurañas y desconfiadas. La estampa pintoresca de los delegados zapatistas fue también motivo de burlas. Vestían la mayoría de ellos con su enorme sombrero ancho, pantalones ajustados y camisa campesina. Nótese la descripción peyorativa que de ellos hace Francisco Ramírez Plancarte:

El aspecto de todos ellos era marcadamente montaraz y sus miradas vagas e inciertas: desmelenados, apelmazándoseles en el mentón un sudoriento e inculto matorral de cabellos. ${ }^{38}$

Los delegados ocupaban un lugar en las deliberaciones por el derecho inherente a su rango militar o mediante la acreditación que le había expedido un representante debidamente autorizado. Además, los convencionistas de ninguna manera se consideraron sólo una junta consultiva como pretendía Carranza y apologistas, sino la instancia de gobierno suprema del país, con facultades soberanas.

38 Ibid., pp 135. 
En varios sentidos, la Convención Revolucionaria de Aguascalientes fue una simulación. Por ejemplo, al reanudarse las sesiones el 10 de octubre el ambiente era magnífico, esperanzador y de aparente camaradería y solidaridad revolucionaria pues se reunieron un grupo de hombres sencillos «inspirados en un gran patriotismo para resolver todas las cuestiones... y lograr la unificación de todos los revolucionarios, con lo cual se lograría la pacificación del país...» ${ }^{39}$ Sin embargo, sólo fue un arrebato patriótico inicial pues bajo la apariencia de un acuerdo unánime respecto a los fines de la Convención, muy pronto surgió y prevaleció ese ambiente cargado de escepticismo y desconfianza. Las relaciones entre los caudillos, ya muy deterioradas por los odios y celos mutuos, alcanzó a los delegados, muchos de los cuales fueron incapaces de desprenderse del espíritu de cuerpo o faccional o bien se creyeron impedidos de prescindir de los personalismos.

\section{INCIDENTES, NEUTRALIDAD Y CENSURA}

El lunes 19 de octubre se puso en el tapete de la discusión un asunto delicado: la cuestión de si Aguascalientes era o no una región efectivamente neutral que garantizara la tranquilidad y seguridad de los delegados para poder debatir libremente y sin temor alguno. Y es que el fin de semana, en el que no hubo sesiones, ocurrió un suceso importante y hubo algunos incidentes desagradables.

En primer término, el general Francisco Villa se hizo presente ante la Convención para jurar lealtad (aunque no hubo sesión), posó para la foto, firmó sobre la bandera nacional e hizo público su deseo de no ambicionar puesto político alguno. ${ }^{40} \mathrm{~A}$ las afueras

39) Vito Alessio Robles, Op. cil., p. 131.

40 José C. Valadés, $O p$. cil., tomo IV, p. 54. Este autor afirma que mientras Villa hacía acto de presencia en el Teatro Morelos, sus fuerzas silenciosa- 
del Teatro Morelos, antes de partir hacia su cuartel general, en Guadalupe, Zac., Villa y Obregón se dieron un abrazo de aparente amistad. En segundo lugar, causó profunda tensión la concentración de numerosas tropas y pertrechos de guerra a lo largo de la frontera norte del estado de Aguascalientes, así como otras fuerzas en los límites entre San Luis Potosí y Zacatecas, ${ }^{41}$ y más aún se interpretó como una seria amenaza el hecho de que 18 mil efectivos villistas avanzaron con todo y bestias hasta Rincón de Romos, Ags., con el propósito de procurar alimento para la tropa y los animales, ya que en Zacatecas no lo había, dijo el villista Roque González Garza. ${ }^{42} \mathrm{Al}$ parecer la presencia del general Francisco Villa en Aguascalientes y la estancia provisional de una numerosa fuerza militar de la División del Norte a tan sólo 55 kilómetros de la ciudad capital, sede de la Convención, incomodó a algunos delegados que la consideraron como una especie de violencia simbólica.

Lo anterior, aunado a una serie de incidentes desagradables propiciados por soldados villistas, que en estado de ebriedad amenazaron y molestaron a varios delegados, tanto en la plaza principal como en las cercanías a la estación del ferrocarril para obligarlos a gritar vivas al Centauro del Norte, fue interpretado como una amenaza a la neutralidad de la ciudad y falta de garan-

mente se posesionaron de la ciudad, lo cual no es verdad pues en caso de haber ocurrido tal ocupación militar, los delegados lo hubieran dicho en la Convención.

11 CTA, SD. Departamento de Estado, Asuntos Internos de México, Asuntos Políticos, localización 13415. En adelante citado CTA, SD, 812.00/13415; APJEC, XXI, caja 18, leg. 1843, carta que envía Manuel Rivas, Secretario de gobierno del estado de San Luis Potosí a Venustiano Carranza el 24 de octubre de 1914.

Crónicas y debales de las sesiones de la Soberana Convención Revolucionaria, $2^{a}$. Ed., México, Talleres Cráficos de la Nación, [conmemoraciones cívicas de 1964. Florencio Barrera Fuentes, introducción y notas], 1977, Tomo I, p. 319. En adelante citado Crónicas y debates. 
tías reales para los pobladores y seguridad efectiva para los delegados a la Convención.

Todo se derivó de una proposición de los generales Gregorio Osuna y Alvaro Obregón, para que la Convención diera los pasos necesarios para neutralizar de una manera efectiva a la ciudad. Los villistas se sintieron aludidos y ofendidos, particularmente.el coronel González Garza quien acusó al general Villarreal de estar enterado personalmente de esos asuntos, haber aceptado tácitamente, y a pesar de ello sacarlo a colación en una sesión pública. Viendo la coyuntura, varios delegados carrancistas aprovecharon la ocasión para narrar ciertos abusos de que habían sido objeto y valerse de ello para propagar entre los asistentes la idea de que la ciudad estaba amagada por la División del Norte y se carecía de garantías. Por ejemplo, el delegado Murrieta, perteneciente a la facción carrancista, contó que había sido «ultrajado en la plaza pública por algunos soldados ebrios; algunos de los compañeros estaban conmigo... al salir de la Convención... nos pusieron la pistola en el pecho, obligándonos a decir que viviera Villa... ${ }^{43}$ De igual manera, el delegado Orestes Pereyra, de la División del Norte, se quejó que soldados villistas habían sido molestados por tropas carrancistas apostadas en La Cantera, hacienda distante 10 kilómetros al sureste de la ciudad. ${ }^{44}$

El general carrancista Guillermo García Aragón, miembro de la Junta Neutral de Gobierno, ${ }^{45}$ se justificó al señalar que no se contaba con fuerzas reales para guardar el orden y garantizar la seguridad personal de los miembros de la Convención, ya que sólo contaba con cien policías para cuidar a toda la población. Lo cierto es que la región desde hacía varios meses acusaba un pro-

43 Crónicas y debaies, Op. cil., tomo I, p. 318; Francisco Ramírez Plancarte, Op. cit., pp. 109-110.

44 Crónicas y debales, Op. cit., tomo I, p. 321; Vito Alessio Robles, Op. cil., p. 146.

45 CTA, $S D, 812.00 / 13437$. 
blema grave de inseguridad pública que no había podido resolver las autoridades. La presencia de fuerzas militares en la ciudad y personas de origen desconocido que delinquían en las cercanías de la capital fue motivo de conflicto constante. Estuvieron a la orden del día los robos, confiscaciones, clausura de establecimientos; personas heridas, secuestradas y asesinadas; fueron frecuentes los casos de escándalos en la vía pública por riñas, embriaguez y prostitución. Los cien gendarmes del cuerpo de policía de la capital de Aguascalientes se vieron en la imposibilidad de dar garantías a la población. El número insuficiente de guardias de seguridad, el escaso armamento con que contaban y el nulo respeto de parte de las fuerzas militares que guarnecían la plaza, obstaculizaron el iden.

Los desmanes y atropellos a que hacían referencia algunos delegados se debía, en suma, a la inercia del momento revolucionario que se vivía, al exceso de soldados irresponsables y prepotentes que deambulaban por las calles en estado de ebriedad. Muchos de ellos eran en realidad asistentes de los delegados o pertenecían a la escolta personal de los jefes militares de las distintas facciones que acudieron a la Convención y que bajo los influjos del alcohol cometieron atropellos contra la población en general, agentes de seguridad y miembros de la asamblea revolucionaria.

Los delegados carrancistas aprovecharon para señalar que la neutralidad era una farsa, y tanto tácita como explícitamente, aprovecharon para acusar a las fuerzas de la División del Norte de amagar la neutralidad de la ciudad. Gregorio Osuna y Antonio ı. Villarreal inclusive propusieron que la Convención se mudara de sede si no se garantizaba la neutralidad, propuesta que no fructificó pues se corroboró que no existía tal amago. ${ }^{46}$

46 Vito Alessio Robles, Op. cil., pp. 145-150. Para este autor la propuesta de traslado de la Convención a otra ciudad no fue más que una maniobra infructuosa de la facción carrancista, proposición que sin embargo sembró la 
Como a todos los delegados les interesaba que se guardara el orden en la ciudad y que los deliberantes gozaran de garantías para discutir y actuar con absoluta libertad y sin ningún tipo de presión, se aprobó una proposición de los delegados David G. Berlanga y del coronel Roque González Garza orientada en ese sentido. Había que reconocer primero que en Aguascalientes ya había un gobierno constituido, cuya cabeza del poder ejecutivo era el coronel Alberto Fuentes Dávila, y dada la situación especial de la ciudad, entonces se requería una junta neutral conformada por dos personas más, que conjuntamente con el gobernador colaboraría en la difícil función de llevar a la práctica la conservación del orden en todo el territorio de Aguascalientes y otorgar garantías tanto a la población como a los delegados. De modo que la Convención ratificaría los nombramientos ya expedidos en favor de Fuentes Dávila y los generales Agustín García Aragón y Fidel Ávila, o bien nombrar otros para luego concederles reconocimiento legal como miembros de la Junta Neutral de Gobierno. Para poder exigirle responsabilidad, antes se le debía conceder amplias facultades, proporcionarle los elementos materiales necesarios así como otorgarle libertad de acción, respetar sus funciones y no invadirlas. ${ }^{47}$ Varios delegados sugirieron como posibles soluciones prohibir la venta de bebidas embriagantes, aminorar el número de soldados en la ciudad o dejarlos acuartelados, que los jefes tuvieran máximo dos asistentes así como un mayor y mejor control sobre las tropas indisciplinadas, retirar las tropas fuera del territorio de Aguascalientes, que ningún jefe moviera tropas sin la autorización de la Convención, dejar una agrupación de soldados bajo las órdenes exclusivas de la Junta Neutral de Gobierno, etc. ${ }^{48}$ Muy pronto la junta neutral de gobierno se abocó

duda y la desconfianza.

47 Crónicas y debates, Op. cil., tomo I, pp. 324, 327, 362.

48 Ibid., tomo I, pp. 319, 320, 321, 329, 330, 331, 332, 333, 352 
a realizar las primeras gestiones, y el día 21 de octubre ordenó que Tomás Urbina sacara sus tropas de Rincón de Romos y las llevara fuera del territorio de Aguascalientes, orden que fue acatada ese mismo día y sin problemas por el general villista; además, impuso la censura en el telégrafo al prohibir que fuera pasado cualquier mensaje en clave o cifrado. ${ }^{49}$ Se había dado un paso importante en la neutralización del estado y con ello se tranquilizarían los ánimos por un tiempo entre los delegados, no así en la insidiosa prensa carrancista metropolitana.

Durante ese día y los subsiguientes continuaron llegando toda clase de comunicados que evidenciaban la falta de voluntad de las partes en conflicto para acatar las órdenes de la Convención. Valiéndose de todo tipo de argucias se ignoraban làs disposiciones y con su desacato ponían en entredicho la soberanía de la Convención. Por ejemplo, Berlanga y otros tres delegados propusieron se solicitara a Carranza, Villa y Maytorena un «estado de fuerzas», en el que señalaran el número de elementos con que contaban las tropas de sus dependencias, con anotación del efectivo de cada destacamento y los puntos territoriales en que se encontraban, además de que se les prohibió hacer algún movimiento militar sin previa autorización de la Convención. ${ }^{50}$ Evidentemente se estaba buscando que ésta adquiriera respetabilidad, tratando de hacerse obedecer por los caudillos, sin importar su jerarquía. Buscaban que ninguna fuerza revolucionaria siguiera reclutando más soldados, evitara provocaciones, movilizara tropas, ganara terreno, atacara al enemigo y le causara bajas. Constantemente la asamblea exhortaba al cese de hostilidades y ordenaba la liberación de presos políticos, en fin, exigía obediencia y

49) Crónicas y debates, Op. cil., tomo I, pp. 391, 392, 395, 417; CTA, SD, 812.00/ 13449 , mensaje cifrado de Carothers al secretario de Estado norteamericano.

50 Crónicas y debales, Op. cil., tomo I, pp. 351, 371, 372; Luis Fernando Amaya, Op. cit., p. 125. 
amenazaba con imponerse por la fuerza para hacer la paz, pero lo cierto es que era constantemente burlada.

PRENSA CARRANCISTA: CENSURA Y MANIPULACIÓN

El Primer Jefe continuaba desentendiéndose de la invitación para asistir a Aguascalientes o enviar un representante, a pesar de que se le invitó reiterada y formalmente; únicamente contestaba de enterado y agradecía la invitación. ${ }^{51}$ Carranza no tenía la intención de obedecer ni acatar la soberanía de la Convención, simple y sencillamente porque nunca estuvo dispuesto a renunciar al poder político adquirido. Con antelación empezó a abonar el terreno.

Venustiano Carranza y su grupo de intelectuales sabían la importancia de la prensa. Ante la inminencia de un conflicto armado, la prensa sería una arma más. Su papel: controlar la información y manipularla en el sentido que más conviniera a sus intereses. La prensa capitalina, muy pendiente de lo que acontecía en Aguascalientes envió reporteros y fotógrafos para cubrir la noticia de tan importante suceso, de cuyos debates se definiría el futuro político y militar del país. Los diarios El Pueblo y El Liberal, subsidiados por el carrancismo publicaban encabezados, editoriales y crónicas sobre la Convención que se verificaba en Aguascalientes, noticias que sembraron la duda, la división, la desmoralización y la incertidumbre entre la expectante opinión pública.

La facción carrancista y todo su aparato editorial mostró el siguiente comportamiento hacia la Convención: transitó de la desconfiada cautela, pasó por los ataques velados, hasta llegar a la agresión franca y abierta. La parte neural de las agresiones se concentraría en la cuestión de la soberanía. Los periodistas Ciro

Crónicas y debates, Op. cit., tomo I, p. 350 
B. Ceballos y Heriberto Barrón escribieron en El Liberal, en tono sarcástico, secundados por afamados jurisconsultos, editoriales y artículos en los que se ridiculizaba la «pretendida soberanía de la Convención», ${ }^{52}$ soberanía que por supuesto ponía en entredicho el poder político del primer jefe.

A varios delegados les molestaba que el público de las galerías, entre quienes se encontraban periodistas de la prensa nacional y extranjera, trataba de intervenir e influir en los debates al manifestarse en pro o en contra mediante gritos, aplausos, siseos y burlas. De allí la insistencia recurrente de entrar en sesión secreta, donde además de tratar asuntos delicados se buscaba excluir a la prensa y al público. Se llegó incluso a proponer se impidiera la entrada del público a galerías, y enterarlo más tarde mediante boletines pegados a la entrada del edificio. ${ }^{53}$ La prensa, por otro lado, fue en lo sucesivo vista con desconfianza y hasta acusada directamente de actuar de mala fe, de no conducirse con verdad, de tergiversar los hechos. Y es que en la prensa capitalina, subsidiada por el Primer Jefe, nada más estaba buscando la ocasión, dijo un delegado, para «meter cizaña y llevarnos quizás a un abismo" $;{ }^{54} \sin$ lugar a dudas la información era sometida a censura y publicada de una manera distorsionada en el sentido de hacer creer a la opinión pública que los delegados estaban en cautiverio, amenazados, bajo un reino de terror ${ }^{55}$ y bajo presión moral y material y por ello no debatían con entera libertad, todo lo cual se traducía en una labor con efectos perversos contra la Convención. Los efectos: sembrar la duda y la desconfianza acerca de los resultados satisfactorios de la Convención cargando la atmósfera de pesimismo, encender los ánimos y sublevar las pa-

\footnotetext{
52 El Liberal, 19, 21, 24 y 25 de octubre de 1914.

53 Crónicas y debates, Op. cil., tomo I, p. 427.

51 Ibid., tomo I, p. 457.

55 CTA, SD, 812.00/13553.
} 
siones entre las distintas facciones y, en general, fomentar el divisionismo y la desmoralización así como «envenenar la opinión pública». ${ }^{56}$

La Convención tomó cartas en el asunto, aunque no lo consideró como de urgente resolución ${ }^{57}$ lo cual prueba que no era un problema que les preocupara demasiado. Hubo opiniones encontradas en el sentido de si se levantaba una enérgica protesta o no, así como exhortar a los corresponsales tanto de la prensa del país como extranjera a conducirse con verdad en sus reportajes y exigir que los directores de sus respectivos periódicos publicaran íntegras sus notas. De lo contrario, es decir, si no se cumplían las disposiciones de la Convención, entonces serían expulsados de la entidad y no se les permitiría en lo sucesivo asistir a los debates. ${ }^{58}$ Por otro lado, la Junta Neutral de Gobierno dispuso que en telégrafos se estableciera la censura para impedir que los reporteros enviaran sus notas en mensajes cifrados, pero resultó que entre los telegramas detenidos estuvo uno del delegado Gregorio Osuna que intentaba comunicarse con su representado, el general Jesús Carranza, todo lo cual causó molestia al agraviado. ${ }^{59}$ Berlanga se manifestó en contra de cualquier tipo de censura, y externó su opinión en favor de la libertad de prensa, a pesar de los riesgos que ello implicaba. Afirmó que él no se sentía particularmente agraviado, que las calumnias no le afectaban, ni se sentía desde luego cohibido por ninguna fuerza moral o material. Pero en su opinión no era necesario utilizar medios que calificó

56 Crónicas y debates, Op. cil., tomo I, pp. 480, 349, 381, 394, 395, 407; Francisco Ramírez Plancarte, Op. cit., pp. 111-119.

57 Crónicas y debales, Op. cit., tomo I, p. 426.

58 Robert E. Quirk, La Revolución Mexicana 1914-1915. La Convención de Aguascalienıes, Aguascalientes, Gobierno del estado de Aguascalientes, 1989, [comisión para la conmemoración del LXXV aniversario de la Soberana Convención Revolucionaria de Aguascalientes] pp. 89-90; Crónicas y debates, Op. cit., tomo I, pp. 381, 394, 454.

s9) Crónicas y debales, Op. cil., tomo I, p. 417.

152 C A A 
de indecorosos como los empleados por los periodistas insidiosos, pues si se tenían convicciones no había necesidad de hacer caso a insultos e informaciones insidiosas, a menos que algún delegado en lo personal se sintiera particularmente aludido y deseara protestar en lo particular. Señaló, como para reafirmar su espíritu independiente y su libertad de criterio que él nunca había tenido en el pasado freno alguno ni lo aceptaría en el futuro "porque lo he dicho y lo diré: yo no acepto ninguna tiranía...» ${ }^{60}$ Además enfatizó:

... no debemos comenzar nuestras deliberaciones poniendo un freno a la prensa, creo que precisamente escuchando la opinión de todos, y viendo como pensamos amigos y enemigos, podemos perfectamente normar nuestra conducta. No creo de ninguna manera un acto justo poner una mordaza a los escritores; comenzaríumos por fundar una tiranía. ${ }^{61}$

Su propuesta no fue aprobada. Berlanga terminó por reconocer que Venustiano Carranza era el responsable principal, además de los directores de los periódicos, de las noticias aparecidas en la prensa que él sostenía económicamente y terminó adhiriéndose al voto de censura; ${ }^{62}$ la asamblea votó en favor de emitir enérgica protesta contra los periódicos de la ciudad de México, por haber aseverado que los miembros de la Convención estaban cohibidos para deliberar libremente. ${ }^{63}$ Por otro lado, se acordó que la asamblea revolucionaria tuviera su propio órgano de difusión en el que se publicaran los debates, acuerdos y otras noticias relacionadas con la vida de la Convención. Dicha publicación llevó por nombre precisamente La Convención y su director fue el polémico escritor queretano, Heriberto Frías. ${ }^{64}$ Con esta

\footnotetext{
60 Crónicas y debales, Op. cil., tomo I, p. 482.

61 Ibid., p. 479.

62 Ibid., p. 483-484.

63 Ibid., pp. 460, 478-490.

(n) Heriberto Frías, exteniente del ejército federal, bohemio, de personalidad
} 
medida se buscaba contrarrestar la creciente influencia de la prensa carranista, en un nuevo episodio de la lucha interrevolucionaria, dando paso a la guerra de papel.

\section{CONSIDERACIÓN FINAL}

No es propósito de este trabajo hacer el seguimiento del comportamiento de la prensa carrancista y convencionista en torno a la Soberana Convención Revolucionaria posterior a la etapa en que este organismo estuvo en el Teatro Morelos de Aguascalientes. Cabe señalar, en todo caso, que tras el rompimiento entre Venustiano Carranza y la Convención, en diciembre de 1914, sólo quedaba un camino: el de la lucha armada. Sin embargo, de manera simultánea se desarrollaría otro tipo de guerra menos ruidoso pero no menos efectivo: el de la propaganda ideológica. A la postre, el carrancismo saldría triunfador en ambas estrategias, pues a pesar de las profundas divergencias entre sus integrantes, esta facción mostraría a la opinión pública coherencia y unidad en sus medios propagandísticos de legitimidad política, mientras que el convencionismo hizo patente su mayor grado de heterogeneidad al acusar descuido, falta de unidad y contradicciones en sus principales medios de difusión y de propaganda política ${ }^{65}$

tímida y salud enfermiza, Frías agudizó sus ideas de crítica político-social después de la matanza de Tomóchic, Chih. (1892), a través de la publicación de artículos en diarios oposicionistas al régimen porfirista tanto en la capital del país como en la ciudad de Mazatlán, Sin. En enero de 1915 fue nombrado director del diario convencionista El monitor, editado en la ciudad de México, cargo que ocupó hasta el 21 de marzo del mismo año. El monitor, meses de enero a marzo de 1915

6.5 Friedrich Katz, Pancho Villa, México, Era, 1999, tomo 2, pp. 44-55. Un buen ejemplo de la falta de coherencia en un diario convencionista es el caso de El Monilor, pues en un lapso de medio año, entre diciembre de 1914 y junio de 1915, tuvo al menos tres directores: Luis Zamora Plowes, Heriberto Frías y Rafael Pérez Taylor, cada uno de los cuales le dio al diario un sentido y orientación política muy distinto a su antecesor. 